\title{
A comprehensive transmedia activity to commemorate the International Day of Light 2021 on social networks
}

\author{
Carlos Damián Rodríguez-Fernández ${ }^{1, *}$, Bastián Carnero $^{1}$, Mónica Canabal $^{1}$, Damián Ínsua $^{1}$, Alejandro Doval ${ }^{1}$, Alicia \\ Muñoz ${ }^{1}$, Raúl Sánchez ${ }^{1}$, Rocío Liñares ${ }^{1}$, Xoán González ${ }^{1}$, and M.T. Flores-Arias ${ }^{1}$ \\ ${ }^{1}$ USC-OSA Student Chapter and USC-EPS Young Minds Section, Facultade de Óptica, Universidade de Santiago de Compostela, \\ E-15782 Santiago de Compostela, Spain
}

\begin{abstract}
Since the advent of the COVID-19 pandemic, face-to-face outreach has been gradually replaced by dissemination through social networks. However, the use of social networks for outreaching is not easy since there is an important risk of biasing the communication by converting it into an exclusively one-way channel. In this contribution, we explain how a transmedia perspective can transform a regular activity, as a photo contest for the International Day of Light 2021, into an interactive, comprehensive and functional event in Twitter, Instagram and Twitch.
\end{abstract}

\section{Introduction}

Dissemination is a fundamental instrument to explain what scientific research is about, but also to raise awareness about the important role that science plays in our lives. In this context, a number of national and international scientific societies decided to support student chapters, groups of students devoted to dissemination. The USCOSA/USC-EPS is a student chapter composed by physics students from the Universidade de Santiago de Compostela (USC) funded both by the Optical Society (OSA) and the European Physics Society (EPS), which has been active since 2013. Our outreach has been historically focused on raising awareness about the importance of light through face-to-face interactive activities with school and high school students $[1,2]$. However, due to the advent of the COVID-19 pandemic, typical outreach activities were no longer allowed, so we decided to migrate our activity to social networks (SNs).

In this contribution, we present and analyze a comprehensive transmedia activity to commemorate the International Day of Light (IDL) 2021, entitled The bright side of everyday life. This activity involved the use of three distinct SNs: Twitter, Instagram and Twitch, each one selected to host a specific part of the event in accordance with their own distinguishing features.

\section{Dissemination by SNs and transmediality}

SNs are online environments that people use to interact with other people with similar interests and to develop social relationships. It is estimated that, currently, there are

*e-mail: usc.osa.sc@gmail.com more than 4.20 billion of accounts in SNs worldwide, a figure which roughly corresponds to $54 \%$ of the global population [3]. During the pandemic, many outreachers have migrated their face-to-face outreach to $\mathrm{SNs}$, which ensure access to a large number of people while guaranteeing the required social distance. However, using SNs for outreach is not easy because of the limitations of each platform and the inherent risk of biasing the communication by converting it into a unidirectional channel. These drawbacks can be avoided by opting for a transmedia approach [4]. It consists in involving people in an event that is held on different platforms at different times and at different stages. Note that it does not mean to do the same thing on different SNs but to do different actions on each platform as part of a whole. This strategy is very convenient since it allows taking the particular advantages of each platform. However, in order to make it work, the events held in the different platforms must have a common narrative, since only when all the pieces match together a transmedia activity is successfully addressed.

\section{The bright side of everyday life}

The bright side of everyday life is a transmedia activity devoted to commemorate the IDL 2021. The central narrative of the event is a photography contest which looks for the best picture of an optical phenomenon in daily life. From a regular perspective, this activity could be kept in locally spreading the contest, choosing a jury and announcing the winning picture. However, by using a transmedia approach, the photo contest becomes just one piece of a larger event which can be divided in three parts: active promotion, interactive photography contest and awarding by outreaching, each one held in a different $\mathrm{SN}$. 


\subsection{Active promotion: Twitter}

Twitter was chosen as the main platform to actively promote our activity. Twitter is a microblogging SN where users can interact through 280 character-limited messages known as tweets, which also can feature pictures. These tweets can be concatenated to create threads, small segments of information that can be easily consumed and shared. This functionality was exploited to announce and update all the details in relation to the photography contest. Specifically, we created an appealing initial tweet together with a promotional poster (Fig. 1) which worked as a header of a thread that summarized the most relevant aspects of the contest. This thread was periodically quoted and updated to keep the contest up to date for our followers. A final mention must be made regarding language, which must be close and inclusive. This helps people to engage with the activity, which is important for a transmedia event.

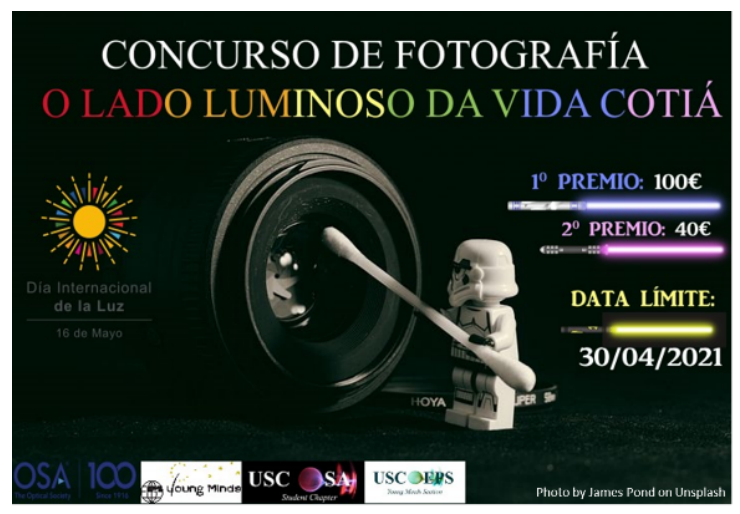

Figure 1. . Promotional poster of The bright side of everyday life transmedia activity. This poster was uploaded to our Twitter profile as a header of a thread where we summarized the most relevant aspects of the contest.

\subsection{Interactive photography contest: Instagram}

Instagram was selected for holding this part of the event since it is the most relevant social network of those devoted to photo sharing and it counts with a large number of users. For the photography contest, we asked for pictures of optical phenomena that could be observed in everyday life together with a brief scientific description of them. In a first round, a jury constituted by professors graded the pictures according to their quality and to the accuracy of the given description. The top ten pictures were published on our profile and the winners were chosen by popular vote. The same day that the voting ended, the pictures were hidden to the public to announce the definitive winners in a specific award ceremony. The implemented two-round vote system has two main benefits. First, the jury vote ensures that the finalist pictures have a high scientific and artistic quality. Second, it generates engagement in our public since our followers are given an active role in the contest. This was especially clear for the authors of the finalist pictures, who competed between them to attract attention, often involving friends and relatives in the event. This dynamic is highly beneficial since it allows reaching people that were a priori not interested in optics, spreading the importance of light. In our case, the finalist photographs collected together thousands of votes and our number of followers increased by 300 .

\subsection{Awarding by outreaching: Twitch}

The awarding ceremony was organized on Twitch, a cutting-edge $\mathrm{SN}$ focused on live streaming, a format which creates a very close feeling in the viewer. Instead of designing a standard award ceremony where the winners are directly announced, the occasion was used to go a step further and disseminate optics. During the live streaming, a group of five members of the chapter reviewed the ten finalist photos (Fig. 2a), analyzing, discussing and explaining the optical phenomena behind each picture in a relaxed talk format (Fig. 2b). The explanation of the photos was previously prepared in detail by the members of the group, so that the phenomena could be explained rigorously.
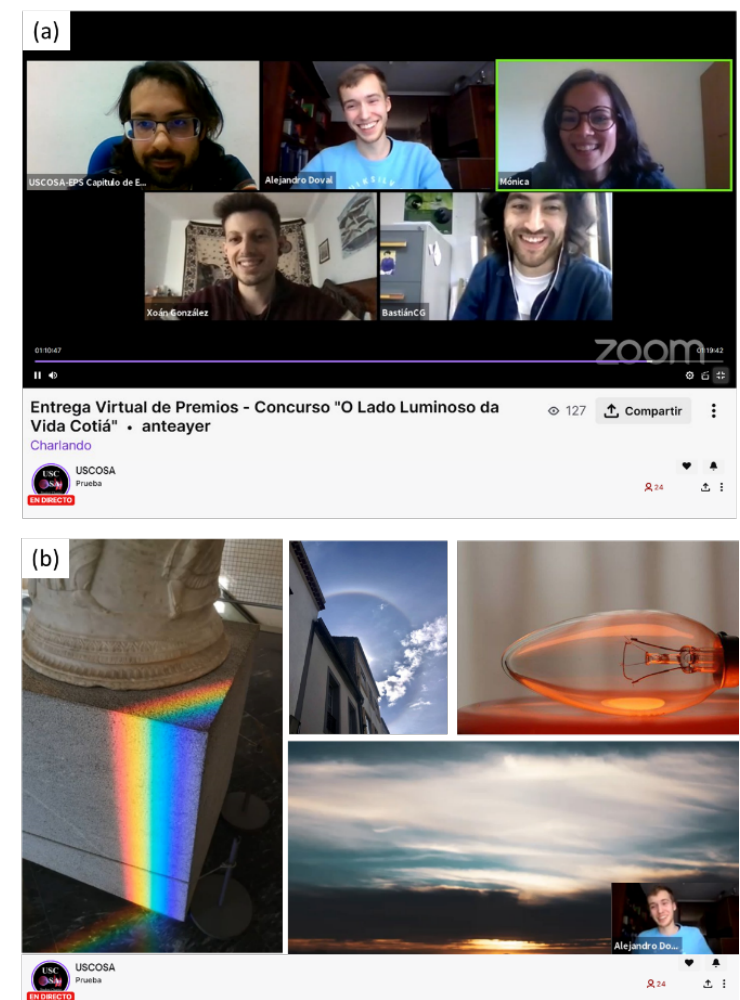

Figure 2. Awarding ceremony of The bright side of everyday life transmedia activity held in Twitch. a) Five members of the chapter participated in the ceremony where b) the analysis, discussion and explanation of the optical phenomena behind each picture was performed in a relaxed format.

To finish, the winner of the contest joined the streaming as a special guest to explain the principal aspects of her photography and to discuss the optics behind. The live award ceremony was followed by about 30 people, however, afterwards, it was watched in delay up to 150 times, which is a clear indicator of the interest generated by our outreach-oriented award ceremony. 


\section{Conclusions}

Transmediality goes beyond outreaching by using different social networks but creating an interactive event with a coherent narrative that flows through different platforms. This approach allows enhancing the engagement of the public by exploiting the specific strengths of each social network while getting rid of their cons. Applying this philosophy, we converted a standard photo contest into a comprehensive experience on Twitter, Instagram and Twitch, including a fluid interaction with our followers and a close but rigorously outreaching award ceremony.

\section{References}

[1] A.I. Gómez-Varela, A. Gargallo, H. González Núñez, T. Delgado-García, C. Almaguer-Gómez,
F. Cambronero-López, M.T. Flores-Arias, The USCOSA Student Chapter: goals and benefits for the optics community, in 12th Educ. Train. Opt. Photonics Conf., edited by M.F.P.C. Martins Costa, M. Zghal (2014), Vol. 9289, p. 92892T, ISBN 9781628413649, ISSN 1996756X

[2] A. Gargallo, A.I. Gómez-Varela, H. Gónzalez-Nuñez, T. Delgado, C. Almaguer, F. Cambronero, Á. GarcíaSánchez, D. Pallarés, M. Aymerich, Á.L. Aragón et al., J. Phys. Conf. Ser. 605, 012040 (2015)

[3] Hootsuite \& We Are Social, Digital 2021 Global Digital Overview (2021)

[4] L. Fleming, J. Media Lit. Educ. 52, 370 (2013) 